\title{
Konzentrationslagern (campos de concentración) en Chile. Sobre la (im)pertinencia del nombre ${ }^{1}$
}

\author{
Konzentrationslagern (Concentration Camps) in Chile. \\ About the (Im)Pertinence of the Naming
}

\section{Konzentrationslagern (campos de concentração) no Chile. Sobre a (im) pertinência do nome}

Dr. José Santos-Herceg²

Recibido: 23/11/2016 - Aceptado: 05/12/2016

\begin{abstract}
Resumen
El texto gira en torno a la pregunta acerca de si es o no pertinente hablar de "campo de concentración", en tanto que traducción del término alemán Konzentrationslager, para designar aquellos lugares que se usaron para detener y torturar en Chile durante la última dictadura militar (19731990). En el artículo se presentan una serie de argumentos que explicarían y fundamentarían dicho uso, para luego plantear algunas objeciones a dichos argumentos que harían necesario abandonar la utilización de esta nomenclatura para designar la realidad de lo ocurrido en Chile.
\end{abstract}

Palabras clave: Chile - campo de concentración - dictadura militar prisión política

\section{Abstract:}

The text revolves around the question of whether or not it is suitable to speak of "concentration camp", as a translation of the German term

1 Este trabajo forma parte de la investigación titulada "Campos prisioneros en Chile. Reconfiguración de los lugares y las subjetividades" (FONDECYT N 1140200). Una versión anterior de este escrito fue presentado en el Seminario Educación, Dictadura, Posdictadura y Totalitarismos, Londres 38, Santiago de Chile, 18 de junio de 2015.

2 Chileno, Licenciado en Filosofía por la Pontificia Universidad Católica de Chile, Doctor en Filosofía por la Universidad de Konstanz (Alemania); Instituto de Estudios Avanzados (IDEA-Usach), jose.santos@usach.cl 
Konzentrationslager, to designate those places that were used to arrest and torture in Chile during the last military dictatorship (1973-1990). The article presents a series of arguments that would explain and justify such use, to then raise some objections to these arguments that would make it necessary to abandon the use of this concept to designate the reality of what happened in Chile.

Keywords: Chile - concentration camp - military dictatorship - political prison

\section{Resumo:}

O texto gira em torno da pergunta sobre si é ou não apropriado falar de "campo de concentração", enquanto a tradução do alemão Konzentrationslager, para designar aqueles lugares que foram usados para prender e torturar no Chile durante a última ditadura militar (1973-1990). No artigo se apresenta uma série de argumentos para explicar e fundamentar tal uso para logo, levantar algumas objecções a esses argumentos que faria necessária abandonar a utilização desta nomenclatura para designar a realidade do que aconteceu no Chile.

Palavras-chave: Chile - campo de concentração - ditadura militar - prisão política

\section{El punto de partida de este escrito es una pregunta planteada muy claramente por María José López. Dice la autora:}
¿Cuál es la pertinencia/impertinencia de utilizar categorías de análisis, vinculadas a experiencias del terror vivido bajo los sistemas totalitarios de la primera mitad del siglo veinte en Europa, específicamente la experiencia del nacional socialismo alemán, en el análisis de las experiencias de las dictaduras latinoamericanas de la segunda mitad del siglo XX en el Cono Sur, y específicamente la experiencia chilena?" (2015b).

Totalitarismo, holocausto, genocidio, solución final, musulmán, etc. Una de estas categorías, la de "campo de concentración", será el objeto de este texto. Respecto de ella, Mariela Avila ha planteado expresamente la pregunta: " ¿es posible hablar de campos de concen- 
tración en América Latina? (222). En esta oportunidad, no obstante, interesa tan solo rastrear si es pertinente o no hablar de campos de concentración en Chile.

Cabe destacar, desde el comienzo, que no se trata de cuestionar en lo más mínimo la existencia ya demostrada de recintos en los que se encerró, denigró, interrogó, torturó, asesinó e hizo desaparecer a miles de chilenos durante la dictadura. Interesa simplemente preguntarse si corresponde o no designar a estos lugares con el nombre de "campo de concentración". La pregunta por la pertinencia del uso de esta categoría llega, sin embargo, algo retrasada. Es un hecho que ella es la más utilizada en Chile para designar estos lugares y prácticamente todos los sobrevivientes utilizan esta nomenclatura; de hecho, el nombre que más aparece en los testimonios es, sin lugar a dudas, el de "campo de concentración". ${ }^{3}$ En el mismo sentido, se puede observar que gran parte de la literatura teórica también la utiliza. ${ }^{4} \mathrm{La}$ pregunta por la pertinencia, por lo tanto, surge cuando la categoría está instalada hace mucho como la nomenclatura habitualmente utilizada y aceptada.

Sin perjuicio de que puedan existir otras, es posible distinguir al menos tres tipos de argumentación que explicarían y fundamentarían el hecho de que se haya utilizado y se utilice aún hoy el término "campo de concentración" en Chile, en tanto que traducción del alemán Konzentrationslager. En primer lugar, se sostiene que la experiencia alemana y la chilena serían semejantes y, por lo tanto, se podría utilizar el mismo nombre en ambos casos. En segundo lugar, se ha explicado que dado lo novedoso que fue para Chile lo ocurrido, no se contaba con categorías para nombrarlo y, por lo tanto, se utilizó la nomenclatura alemana que ya existía y que era conocida. En tercer término, se alude a ciertas razones estratégicas y políticas vinculadas con la denuncia de

3 Como ejemplo se puede ver: Gamboa 2010 14, 97, 185; Joui 1994 57, 73, 140; Aibar 2002 6, 9, 47, 48, 169, 228, 229, 230; Corvalán 2007 31, 32, 34, 36, 50, 51, 54, $63,68,70,87,95,96,102,103,104,108,109,118,123,129$; Villegas 1974 8, etc.). 4 Cf., Peris Blanes 2005; Calveiro 2008; Raffin 2006; Brossat 2006 129; López 2007; Cassigoli 2011; Garretón 1996; Avila 2012, etc.). 
los atropellos a los Derechos Humanos. Con la utilización del nombre alemán su buscó provocar una vinculación del horror chileno con el desencadenado por el nazismo, y con ello despertar la solidaridad internacional y el repudio a lo que estaba ocurriendo en Chile.

2. Es claro para cualquier observador que entre los Konzentrationslagern levantados durante el régimen nazi en Alemania y los lugares en que se detuvo y torturó personas durante la dictadura chilena hay algunos puntos de contacto, algunas semejanzas que saltan a la vista. Sin pretensiones de exhaustividad, se podría decir que ya desde su aspecto hay algo en los lugares usados en Chile que recuerdan a los usados en Alemania. Torres de vigilancia, alambres de púas, armamento pesado, etc. ${ }^{5}$ Por otra parte, hay algo en la desproporcionada magnitud de lo obrado, de lo dañado, que permitiría emparentar ambos fenómenos, pues la desmesura del horror está presente en los dos casos de forma ostensible. En ambas experiencias la cifra de personas dañadas - muertas, torturadas, forzadas a trabajar, etc.- supera con mucho cualquier experiencia anterior, cualquier expectativa supera lo pensable, lo imaginable.

El hecho de que la existencia de estos lugares obedezca a una política de Estado, que sea parte del programa de los respectivos gobiernos también permite establecer un vínculo entre ambos fenómenos. Tal como lo hicieran los nazis, en Chile se generan estructuras administrativas oficiales y otras secretas (las SS en Alemania, la DINA y la CNI en Chile), encargadas de gestionar, con financiamiento público, el funcionamiento de estos lugares. En ambos casos, por otra parte, las

5 En los testimonios chilenos es recurrente la alusión a asuntos de este orden: para las víctimas estos lugares "se ven" tal como los campos de concentración nazi. Dice Rodrigo Rojas, por ejemplo: "Los murallones de piedra canteada del Velódromo nos recordaban tétricamente la Avenida de las Naciones de Buchenwald, el siniestro campo de exterminio del fascismo hitleriano" (16). Por su parte, Corvalán al referirse a Chacabuco dice que es "una copia idéntica de los campos de concentración nazis" (54). Adolfo Cozzi transmite su impresión al llegar a Chacabuco: "-pude divisar el pueblo amurallado, y distinguí un perímetro rodeado de alambradas y torres de vigilancia, igual a las películas sobre campos de concentración alemanes para judíos" (39). Rolando Carrasco está en la misma línea cuando escribe: "Un campo de concentración igual a los de los nazi" (120). 
instalaciones están destinadas a la reclusión de cierto tipo de sujetos: principalmente judíos en el caso nazi, y fundamentalmente miembros de los partidos que apoyaron la UP y dirigentes sindicales o sociales en el de la dictadura chilena. La eliminación de un grupo, ya sea por medio de la muerte o a través del terror y la desarticulación de su organización es, en ambos casos, la finalidad de estos lugares. Exterminio y desaparición forzadas son estrategias diferentes que se emparentan al estar enfocadas en un grupo particular al que se pretende llevar a la extinción.

En lo referente al efecto que se buscaba producir sobre la población con la existencia de estos lugares, coinciden también los Konzentrationslagern con los lugares de detención y/o tortura chilenos. La deshumanización de los internos, en el caso de los nazis, y de los detenidos en el de la dictadura, es el objetivo directo de estos espacios. Hannah Arendt llama a los Konzentrationslagern, como es bien sabido, "laboratorios de la dominación total" (Cf.: Arendt 33). Su análisis busca mostrar cómo en ellos se puede experimentar con la vida de hombres y mujeres al punto de que, en situaciones extremas, se llegue a expulsar todo rasgo de humanidad. El deshumanizar, en el caso de los lugares de detención y/o tortura chilenos, es también el objetivo y se implementa con una serie de estrategias y acciones sistemáticas, rigurosamente aplicadas (Cf.: Avila 2012; Calverio 2006), que son cercanas a las utilizadas en la Alemania nazi: la degradación, la infantilización, el hacinamiento, etc. Lo que se consigue finalmente es lo que dice Quijada en su testimonio cuando señala: "Sí, habíamos dejado de ser personas. Éramos nadie" (153).

Ambos fenómenos son, por lo demás, una parte esencial de un proyecto de reconstrucción y refundación completa. En múltiples oportunidades ha sido puesto de manifiesto que el sistema de los Konzentrationslagern fue fundamental para el nazismo. Arendt incluso sostiene que este tipo de estructuras está en la base del totalitarismo como sistema de dominación total. En el caso chileno, estos lugares fueron fundamentales en lo referente a crear las condiciones necesarias para que los cambios y las nuevas medidas fueran aceptados por la población sin resistencia alguna, pero sobre todo, para la creación 
de un nuevo ciudadano, apto para moverse en el nuevo Chile (Cf.: López y Otero 1989; Vidal 2000).

Finalmente, aunque no por último, se podría decir que emparentan a estos lugares el tener un destino compartido, un desenlace común: su desaparición. Las estrategias o los "operadores" para conseguirlo, como los han llamado Silva y Rojas en el caso chileno (2004 y 2011), son en extremo semejantes a los utilizados en Alemania al terminar la guerra. Compartidas son, por ejemplo, la práctica de la destrucción, la demolición o el desmantelamiento que, según dicen algunos, los uniformados chilenos habrían aprendido directamente de los nazis. ${ }^{6}$ De lo que se habla aquí es de que los lugares, los que ya no son utilizados o una vez terminado el dominio, son reducidos a escombros, transformados en sitios baldíos.

Todas estas semejanzas, estos elementos compartidos, junto con otros que se podrían mencionar, justificarían el haber usado, y el seguir usando, el término "campo de concentración" para referirse a los lugares en los cuales durante la dictadura chilena se detuvo y torturó personas. Esta razón puede encontrarse muy nítidamente en los testimonios de las víctimas, en los que se insiste en hacer alusión a dichas similitudes. Hay alusiones a la semejanza en el modo de trato y las prácticas al interior de los $\mathrm{Campos}^{7}$, hay referencias a que las actitudes de los guardias y oficiales ${ }^{8}$ e incluso a su aspecto físico, como se decía antes, eran parecidos e incluso iguales. En general, la idea que parece estar en el fondo es que, como dice Durán de Puchuncaví, estos lugares "no tenían nada que envidiarle a los campos de concentración de los nazis" (90). El término "campo de concentración" no sería otra cosa más que la traducción del nombre con que durante la Alemania Nazi

6 Escribe Miguel Lawner en su testimonio que "Los fascistas criollos aprendieron las lecciones dictadas por el régimen nazi en los últimos días de la Segunda Guerra Mundial, al hacer desaparecer las huellas del holocausto desencadenado en Europa a medida que se iban retirando de los territorios ocupados" (75).

7 Cf.: Ahumada 2011 100; García 2004 43, 128, 202, 235; Lawner 2004 35; Morales 2003 38, 46; Quinteros 1979 84; Sánchez 2014 123; Vuskovic 1984 68; Aibar 2002 17, 278; Bianchi 2008 60, 101; Bonefoy 2003 75, 128.

8 Caneo 2013 123; Escalona en Denun y Testi 290; Bianchi 200853. 
se bautizó esos lugares análogos en los que se encerraba y eliminaba personas: los Konzentrationslagern.

3. La existencia de elementos compartidos, sin embargo, no fue la única razón por la cual se comenzó a utilizar el nombre en Chile. Este gesto puede y debe entenderse en el marco de una tendencia fuertemente presente, sobre todo en un primer momento, a echar mano del imaginario nazi para representar la catástrofe chilena. Jorge Montealegre, hablando justamente de la utilización de dicho imaginario para describir lo sucedido en Chile, destaca el hecho de que estos lugares en los que se encerraba a la gente, se la torturaba e incluso se la asesinaba, "eran una experiencia inédita para el pueblo chileno y para el mundo respecto de Chile" (123). No existía, ni siquiera, el lenguaje para referirse a ella: no había cómo aludirla, cómo relatarla, cómo nombrarla. En este contexto, como dice Montealegre, "se recurre al lenguaje culturalmente más próximo. En la cultura antifascista su proyección encontraba una relación directa con el imaginario de las atrocidades del nazismo" (íbid.). Tal como señala el autor, el "Holocausto permitía verbalizar de alguna manera lo que no tenía nombre" (126).

Montealegre hace ver que aunque el Holocausto era un acontecimiento lejano para la América Latina, se trataba de algo "cercano culturalmente y presente en los estudios de su pasado reciente" (125). Los jóvenes chilenos sabían del nazismo, del Tercer Reich, de los Campos de Concentración, etc. Sus fuentes no solo fueron la información histórica, sino que también una industria cultural que generó un "imaginario del Holocausto". En los mismos testimonios se alude al hecho de conocer sobre esto a través de las películas (García 236; Cozzi 39 y Carrasco 122). Aunque algunos, como Larrocha, también aluden al estudio directo de la historia (40). Como dice Montealegre, "El imaginario del Holocausto es parte del acervo cultural de la militancia democrática latinoamericana, adquirida por diversos medios formativos y de comunicación que constituyen los soportes y canales de la memoria colectiva" (126). La identificación, en este caso, se produce a raíz de la necesidad de tematizar-de nombrar-una realidad para la que no se tenían categorías, por lo que se echa mano de lo 
más cercano que se tiene para hacerlo: una experiencia que aparecía como análoga.

4. La utilización de la nomenclatura acuñada para el caso de la Shoah para referir lo sucedido en Chile, puede tener -y tuvo claramenteademás un sentido fuertemente estratégico y, por lo mismo, político. Al hacer uso de términos como holocausto, genocidio, campo de concentración, totalitarismo, etc., se genera algo que podría denominarse "parentesco en el horror". Un traspaso opera cuando se utilizan estos términos; uno que permite despertar el mismo espanto, la misma reprobación que existía y existe aún hoy para el caso nazi, pero ahora respecto de lo ocurrido en Chile.

Como muy bien ha hecho ver María José López, el horror nazi se ha vuelto una suerte de arquetipo del horror al que puede llegar una sociedad; es el símbolo paradigmático del horror extremo. Al utilizar sus categorías se busca representar lo vivido en Chile como una manifestación más de dicho horror y, por lo tanto, uno igualmente espantoso, extremo, inimaginable. Si se habla de los "campos de concentración" en Chile, lo que se busca es que en quien lo escuche se disparen una serie de relaciones espantosas, producto de lo sabido sobre los Konzentrationslagern. Esta estrategia está presente muy nítidamente en los primeros años de denuncia, pero sin duda perdura hasta hoy.

Un ejemplo paradigmático de lo que se viene diciendo se puede encontrar en el texto que Friedrich-Karl Kaul presenta en la Tercera Sesión de la Comisión Internacional de Investigación de los Crímenes de la Junta Militar en Chile, que se celebró en Ciudad de México entre el 18 y el 21 de febrero de 1975, y que lleva por título "La congruencia entre el contenido y la apariencia de los sistemas de gobierno fascistas establecidos en 1933 en Alemania y en 1973 en Chile". Allí el autor sostiene, sin dudarlo, que "como prueba de la congruencia entre la dictadura nazi alemana y el régimen de la junta militar en Chile, basta colocar los nombres de Dachau, Sachsenhausen, Auschwitz y Ravensbrück frente a los de isla Dawson, Estadio Nacional, Chacabuco y Pisagua" (Kaul 55). 
5. Esto argumentos son correctos y en muchos sentidos atendibles. En efecto, hay una semejanza indesmentible entre las experiencias alemana y chilena. La prisión política masiva y la tortura sistemática fueron algo completamente nuevo en Chile y, para referirse a ellas, se carecía de categorías. La exigencia de denuncia ante la comunidad internacional hacía razonable establecer una vinculación con la experiencia nazi que permitiera relevar el nivel de horror de que se estaba hablando. Estas razones explican, sin duda, el uso que se ha hecho y se sigue haciendo del término "campo de concentración" para referirse a la realidad chilena. Es posible, sin embargo, introducir una serie de matices en estas razones, además de agregar otros antecedentes que tienen el efecto de poner en duda la pertinencia de seguir utilizándolo, y con ello se haría recomendable abandonar su uso definitivamente.

Se decía, siguiendo a Jorge Montealegre, que la utilización del término "campo de concentración" habría obedecido al hecho de que para Chile y los chilenos lo ocurrido era una experiencia inédita, que tanto las víctimas como los autores se encontraron sin categorías, sin lenguaje para aprehenderlo. Esta decisión de uso, sin embargo, se basó tan solo en un conocimiento habitualmente muy general. Un conocimiento adquirido mayoritariamente por medio de películas, reportajes periodísticos, textos históricos de difusión, etc. El que el conocimiento que sustenta la utilización del nombre sea de "término medio" produce en la práctica una serie de problemas relativos a la traducción, los que en su momento no fueron percibidos y que aún hoy pasan desapercibidos.

El uso del término "campo de concentración" es ya problemático en tanto que traducción del alemán Konzentrationslager. Aunque se trata de una traducción correcta, es necesario anotar que no es la más adecuada. Si miramos, por ejemplo, el término concentration camp utilizado en la traducción al inglés o camp de concentration en francés, notaremos de inmediato un desplazamiento, pues camp no es "campo", sino "campamento". Lager es una palabra de uso cotidiano en el alemán y uno de los sentidos en el que se usa es, justamente, el de "campamento" y alude directamente a una instalación de orden militar. Es este sentido en el que se incorpora en el 
vocablo Konzentrationslager. Si lo que se pretendió fue usar el mismo término alemán traducido, una mejor elección habría sido, siguiendo lo que se ha hecho en inglés y francés, hablar de "campamento de concentración". Referirse a "campos de concentración" en español, como la traducción del término Konzentrationslager del alemán, por lo tanto, es un mal punto de partida.

Por otra parte, es sumamente importante tener a la vista que el término alemán Konzentrationslager no fue el único que se utilizó durante el régimen nacionalsocialista para aludir a los lugares en los que se encerraba y asesinaba personas. En ese contexto, se hicieron distinciones entre los diferentes Lagern y dichas diferencias se reflejan en el uso de nombres distintos. Es así como junto al término Konzentrationslager estaban también los llamados Durchganslager (campamentos de paso), los Frauenslager (campamentos de mujeres), los Jugendslagern (campamentos juveniles) o Jugend-Haftstätten, los Sammellager (campamentos de acopio) o Gettos, los Tötungsanstalten (Instalaciones de/para morir) en donde se llevan a cabo los llamados Euthanasie-Morde y, los más conocidos sin duda, los Vernichtungslagern (campamentos de exterminio). El término Konzentrationslager fue usado fundamentalmente como una suerte de genérico para designar todo este tipo de instalaciones, sin embargo hubo claras distinciones entre ellas, las que se marcaban expresamente con los nombres que se les otorgaban. Todos estos matices y diferencias se pierden en el caso de Chile puesto que se utiliza simplemente el término general de "campos de concentración".

Si lo que se pretendió hacer en Chile fue usar el mismo término utilizado por los nazis para designar sus instalaciones, dicha utilización debería haber sido también análoga y, por lo tanto, se exigiría que el término tuviera una función genérica y luego se distinguieran especies, tipos de "campos" dentro de dicho género. Tanto en los testimonios como en la crítica, sin embargo, se utiliza el término "campo de concentración" de forma algo aleatoria e incluso caótica. En algunas oportunidades designa un tipo de lugar -aunque no siempre el mismo tipo-, en otras oportunidades parece usarse genéricamente, en algunas solo se usa comparativamente, etc. Finalmente, este uso que se hace de un nombre que se toma prestado de la realidad alemana 
termina ocasionando un desorden nominativo que ni siquiera respeta la realidad compleja y específica del acontecimiento chileno.

6. El término mismo Konzentrationslager, por otra parte, es ideológicamente problemático. Se trata, como es evidente, de un nombre fundamentalmente descriptivo: alude a un lugar provisorio -con un sentido cercano a lo militar- en el que se aglutina, se junta, se concentra, en este caso, a personas. Los Konzentrationslagern, fueron, sin duda, lugares de "concentración" de individuos: allí se juntaba mucha gente por períodos relativamente breves de tiempo. La descripción es, entonces, correcta y el nombre sería adecuado. Pese a no ser falsa, ella es, sin embargo, claramente un eufemismo. Se trata de una manifestación suave o suavizada de una idea cuya recta y franca expresión sería dura o incluso brutal. El nombre Konzentrationslager fue acuñado y usado por los mismos nazi, fue el nombre oficial con el que se quiso ocultar, disimular, solapar el hecho de que allí se cometían atrocidades que superaron y aún superan la imaginación más perversa. No deja de ser sorprendente que tanto los testimonios de quienes sobrevivieron aquella experiencia, como la crítica posterior hayan seguido utilizando la nomenclatura del victimario y lo siga haciendo hasta hoy, sin que parezca relevante ni su carácter oficial ni que se trata de un uso eufemístico.

Esta extraña situación podría explicarse si se tiene en cuenta que el carácter eufemístico de este nombre está oculto tras una suerte de resemantización del término. En efecto, hoy en día el vocablo Konzentrationslager, producto de todo un trabajo histórico, cultural, político y de difusión, está asociado con el mayor de los horrores. El signo se ha llenado de nuevos sentidos y parece olvidarse que detrás de él late una intención eufemística originaria. No se puede dejar de observar, sin embargo, el hecho de que el vocablo alemán -así como sus traducciones a los diferentes idiomas- es la nomenclatura acuñada y usada por el victimario -es el nombre de los nazi-; que pese a haber sido re-semantizado, sigue siendo el término nazi y, por lo tanto, aún carga con su sentido eufemístico. Utilizar este nombre implica en alguna medida caer en el juego nazi del nombre que disfraza, que oculta o que, al menos, baja el perfil a lo que allí realmente ocurre. 
El territorio de la lucha por los nombres en Chile ha sido un descarnado campo de batalla, en donde el uso de eufemismos por parte de los victimarios ha tenido y tiene hasta hoy un papel protagónico. A fines de 2011, por ejemplo, el Consejo Superior de Educación determinó que en los textos escolares se cambiara la expresión "dictadura militar" por "régimen militar", al referirse a la forma de gobierno que tuvo Chile entre 1973 y 1990. La medida, que finalmente no se implementó, suscitó una tremenda polémica en la que entraron senadores, parlamentarios e historiadores. Gabriel Salazar señalaba al respecto que "cuando cambian el concepto dictadura, que implica una violación de Derechos Humanos en Chile, por una palabra neutra como es régimen, se disfraza lo que efectivamente ocurrió. No le veo otro objetivo (...), sino que se oculta la realidad por un concepto genérico" (2012). Además de régimen militar hay otros nombres eufemísticos como "pronunciamiento militar" para referirse a "Golpe de Estado", el de "detenidos" para aludir a los "prisioneros políticos", etc.

Entre estos nombres con un fondo eufemístico está el de "campo de concentración" para aludir a los lugares en los que se encerró, maltrató, deshumanizó, torturó, asesinó, violó, hizo desaparecer, etc., a una gran cantidad de personas. El esfuerzo de emparentar el horror del caso chileno con el alemán a través del uso del nombre "campo de concentración" conlleva el riesgo, tal vez inevitable, de que se produzca también una relación con aquel lado del nombre que ha permanecido detrás: aquel que lo vincula con el mundo nazi y su esfuerzo por ocultar con un eufemismo evidente la magnitud de su crueldad.

7. No se trata, sin embargo, solo de un problema de traducción, ni únicamente de un nombre inadecuado, pues también hay complicaciones respecto del referente. Pese a la semejanza entre ambas experiencias, lo que prima al observar comparativamente los Konzentrationslager y los lugares en Chile es, en realidad, la diferencia. En este sentido es que tiendo a coincidir con Mariela Avila cuando señala que "es posible ver ciertas similitudes estructurales entre los campos de concentración latinoamericanos y los Lager nazis. No obstante, es necesario remarcar que estos espacios tienen numerosas diferencias" 
(225). Las diferencias se hacen evidentes tan solo con observar la construcción y configuración de los lugares. Los Konzentrationslagern fueron en su gran mayoría especialmente construidos por el régimen nacionalsocialista. ${ }^{9}$ Al observar el listado de los lugares usados para detener y torturar en Chile destaca, por el contrario, que prácticamente ninguno de ellos fue construido explícitamente para estos propósitos. A diferencia del caso nazi, no se trató de construcción alguna sino de reconfiguración de lugares ya existentes.

Por otra parte, según señala Arendt, los Konzentrationslagern exigen el más completo y estricto aislamiento del exterior (1998 533). Consecuentemente, no hay ninguno que haya sido construido al interior de una ciudad, en medio del mundo urbano: se escogían lugares aislados, pero con buen acceso ferroviario para el transporte de los prisioneros. Como es bien sabido, la gran mayoría de los lugares de detención y/o tortura en Chile, salvo algunas excepciones, se encontraban enclavados en la mitad de las ciudades, de hecho, en su centro mismo. Los Konzentrationslager nazi y la experiencia chilena se diferencian también en lo relativo a la población de estos lugares: no es lo mismo ser un "deportado" en la Alemania nazi que un "prisionero de guerra" o un "detenido político" en el Chile dictatorial. El estar apresado en un Lager no tenía que ver necesariamente con una filiación o militancia política, mientras que, como ha dicho Avila, en Chile es justamente esta la razón por la cual alguien es detenido y desaparecido (225). No era el elemento biológico-religioso, como lo fue en los Lager, sino uno de carácter ideológico el que determinaba que alguien fuera encerrado, torturado $y$, eventualmente, hecho desaparecer. ${ }^{10}$

9 Los únicos lugares ligados a este proceso que no se construyen expresamente son los llamados Tötungsanstalten que fueron seis. Un ejemplo de ello es el castillo Sonnestein en Pirna, cuyo sótano se habilitó para asesinar a deficientes mentales. Se podrían mencionar también casos en los que se utilizó como base alguna estructura ya existente, como sería Dachau, que se construye sobre una fábrica de pólvora abandonada cerca de München. En el sistema de campos de concentración y exterminio que se conocen con el nombre de Auschwitz en Polonia, una de las instalaciones que lo compone se construye a partir de unos barracones del Ejército polaco que estaban en desuso. La gran mayoría de las instalaciones, sin embargo, se levanta a partir de cero.

10 Cabe hacer notar, sin embargo, que esta diferencia es solo válida para el "tercer 
En la estructura de funcionamiento también hay una diferencia evidente: en los Konzentrationslagern son los llamados Kapos quienes tienen el poder en la vida cotidiana. Estos deportados que eran puestos en situación de mando y privilegio por los agentes de las SS, no tienen en el caso de chileno una figura análoga, ni siquiera parecida. Quienes tienen a su cargo la administración de la cotidianidad en estos lugares usados para la detención y la tortura son los "guardias", es decir, agentes de las Fuerzas Armadas y de Orden. ${ }^{11}$ Por otra parte, si hay algo que caracterizó a los Konzentrationslagern desde el punto de vista de su funcionamiento fue que los deportados eran sometidos sistemática y permanentemente a trabajos forzados, incluso haciéndolos trabajar hasta morir. Los trabajos forzados, según dice Garretón, sólo se dieron en algunos lugares en Chile, ${ }^{12}$ lo que se corrobora en los testimonios de los primeros años. ${ }^{13}$ Hasta donde se puede observar, sin embargo, en ninguno de estos lugares se hizo trabajar a los prisioneros como modo de exterminio colectivo, ni hay noticias de que el trabajo forzado fuera utilizado como fuerza productiva del modo como lo hicieron los nazis. ${ }^{14}$

período" de los Konzentrationslagern, pues en un primer momento, estos efectivamente albergaron a los opositores políticos del nacionalsocialismo.

11 Marcia Merino señala en su testimonio que: "En general, los guardias eran jóvenes, seguramente conscriptos; o si eran de planta de alguna institución armada, eran de baja graduación. El nivel educacional era escaso" (40).

12 Según este autor, hay campos que están destinados a la "detención y prisión", otros que fueron creados con el objetivo de "interrogar" y "torturar", y además están las instalaciones de "exterminio masivo" y eliminación de individuos. Menciona, además que hay algunos Centros cuya finalidad habría sido los "trabajos forzados", ya sea con el objetivo de castigar o de producir (1996 6-7).

13 En Dawson, por ejemplo, efectivamente se forzó a trabajar a los prisioneros: Miguel Lawner da cuenta detallada, por ejemplo, de la instalación de postes a la que fueron forzados o a las reparaciones que se les obliga a hacer en el Puesto Harris. Witker, por su parte, relata de qué manera los prisioneros en Isla Quiriquina fueron obligados a refaccionar completamente el antiguo fuerte, ahora como cárcel.

14 En muchos de los Centros los prisioneros trabajaban, lo que generaba una verdadera industria, pero los detenidos no eran forzados a hacerlo, sino que constituía una manera de ocupar el tiempo haciendo algo útil que, eventualmente podría incluso brindarles algún beneficio económico. 
Lo que sí se practicó en Chile de forma sistemática y constante fue la tortura (Cf.: Avila 227). Ella ocupa un lugar central en lo que fue la prisión política en Chile: prácticamente todos quienes fueron detenidos la sufrieron en alguna de sus múltiples modulaciones. Su uso sistemático fue reconocido oficial y expresamente por el Estado chileno a través del Informe que redactara la Comisión Valech (2003-2004). Por el contrario, en los Konzentrationslagern la tortura no tiene un lugar protagónico y su incidencia solo podría constatarse en tanto que castigo y de forma excepcional. Si bien no fue una práctica sistemática en el caso nazi, sin duda la crueldad tuvo allí sus maneras particulares de expresarse. La experimentación médica con los deportados que se lleva a cabo de forma continua y despiadada en los Konzentrationslagern es un excelente ejemplo de ello. Uno que, vale la pena apuntar, no se da en los lugares de detención y/o tortura chilenos. En Chile existió el uso de drogas para interrogatorios, sin embargo, no hay antecedente de que se hiciera trabajo de laboratorio usando a los detenidos como "sujetos de prueba" o "conejillos de indias".

La muerte es, en todo caso, un habitante permanente tanto de los Konzentrationslagern, como de las instalaciones chilenas en las que se detuvo y torturó. Considerando solo un punto de vista cuantitativo ambas experiencias de muerte difieren, sin embargo, radicalmente. En el caso de los Konzentrationslagern se habla de entre 15 y 20 millones de muertos, ${ }^{15}$ mientras que en Chile la Comisión Rettig habla en su Informe de 2.298 víctimas fatales por motivos políticos en el período 1973 - 1990. Aunque la Comisión Valech aumenta posteriormente a 3.065 las víctimas, es evidente la disparidad de ambas experiencias. Desde el punto de vista cualitativo sus diferencias son, por lo demás, radicales: la utilización industrial de estrategias de exterminio masivo como las cámaras de gases, los transportes o el trabajo forzado hasta la muerte, no se dieron en Chile. En el marco de la desaparición y muerte de personas, en dicho caso es posible hablar de estrategias como la ley de fuga, los fusilamientos, la tortura con consecuencia

15 http://www.abc.es/cultura/20130305/abci-nuevo-estudio-sobre-holocausto-201303051315.html 
de muerte. Ninguna de estas formas tiene el tono masivo e industrial que sí tuvo en el caso nazi.

Lo anterior se explica dado que los Konzentrationslagern y las instalaciones que se usaron para detener y torturar en Chile difieren claramente en cuanto a sus finalidades. El objetivo del nazismo al construir y mantener los Vernichtungslagern (centros de exterminio) fue la llamada "Solución final" (Endlösung), que también se conoce como "Solución final de la cuestión judía" (Endlösung der Judenfrage), y que consistía, como es bien sabido, en la muerte de todos los judíos existentes en el territorio de control alemán. Las llamadas "deportaciones" tienen el objetivo de enviar a dichas personas hacia su exterminio. Es un hecho indesmentible que el exterminio se dio en Chile, sin embargo, la eliminación de personas no parece haber sido el objetivo fundamental con el que surgieron la mayoría de estos lugares. Las finalidades fueron múltiples y van desde castigar, vengarse, obtener información, desmantelar la Izquierda, controlar y destruir cualquier tipo de oposición, hasta corromper las estructuras y lazos sociales, pasando por esparcir el miedo y la desconfianza en la sociedad. Para la consecución de estos objetivos la tortura fue una herramienta fundamental. Es en este sentido que López y Otero hablan de la tortura como una forma de pedagogía. ${ }^{16}$ Se podría pensar en los centros de tortura, por lo tanto, como instituciones educacionales en las que -a través de las cuales- se enseña a toda la sociedad el miedo, la desconfianza, la obediencia, etc. Para que esto fuera efectivo, sin embargo, las víctimas debían permanecer con vida: su eliminación masiva nunca fue el objetivo.

Pese a sus semejanzas, las diferencias entre los Konzentrationslagern en la Alemania nazi y los lugares para detención y de tortura en Chile son tales, que razonablemente podría plantearse que el nombre no puede ser el mismo. Difícilmente podría usarse el mismo nombre

\footnotetext{
16 "La tortura educa: reemplaza la crítica por el consentimiento. Modela de una cierta manera que interesa al poder. Es una forma de pedagogía, pero en su propia versión: es una pedagogía del terror" (López y Otero 77).
} 
considerando que se trata de fenómenos que, pese a compartir algunas características, son profundamente distintos. Es posible sostener que entre ellos hay tan solo una suerte de "aire de familia", pero ante referentes distintos, no parece razonable utilizar el mismo signo.

8. Con el uso del término "campo de concentración", se pretendió, como se dijo, provocar en el interlocutor una relación directa con lo ocurrido en los Konzentrationslagern. Es lo que se ha denominado antes "emparentar en el horror". Esta estrategia, sin embargo, acarrea riesgos. El primero de ellos es el riesgo de negar la especificidad de lo ocurrido durante la dictadura chilena. Utilizar las categorías acuñadas para designar el fenómeno europeo con la intención de emparentarse con esa experiencia horrorosa y, de este modo profitar del efecto que tiene el caso nazi sobre la imaginación, nos pone, una vez más, en una situación de dependencia que finalmente provoca la idea errada de que en Chile no ha ocurrido nada nuevo, nada específico. Más aún, ocasiona que se piense que nada extraordinario pasó durante la dictadura militar. Se habría tratado simplemente de la repetición, de una nueva manifestación de algo ya conocido, de un fenómeno ya experimentado en la Alemania nazi.

Esto tiene una consecuencia evidente sobre los trabajos y estudios acerca del tema, pues de lo que se trataría sería simplemente de aplicar al caso chileno las estructuras teóricas y las reflexiones conceptuales que ya se han construido para pensar los campos de concentración nazi. La realidad de los estudios sobre estos lugares en Chile demuestra la efectividad de lo que se dice, pues allí los referentes constantes y permanentes son los trabajos de Giorgio Agamben, y de Hannah Arendt, aunque también se pueden encontrar aludidos autores como Michel Foucault, Robert Antelme, Walter Benjamin, Viktor Frankl, entre otros. Los lugares de detención y de tortura en Chile son estudiados en tanto que "campos de concentración" y, por lo tanto, se les aborda desde la literatura existente al respecto, dando cuenta con ello de una evidente dependencia teórica.

Consecuentemente, insistir en la utilización de la categoría Konzentrationslager, es decir, insistir en el uso del nombre "campo de concentración" para el caso chileno, y la consecuente homologación de 
ambas experiencias puede producir una enorme frustración en quien se interesa en el tema. La frustración se produce cuando los investigadores simplemente no logran encontrar lo que buscan. Quien tenga a la vista el caso nazi buscará en Chile, por ejemplo, trabajos forzados, exterminios industriales, experimentación médica, musulmanes, kapos, etc. Por muchos esfuerzos que haga, por mucho que flexibilice su análisis buscando cosas "análogas", finalmente no encontrará nada de eso y la frustración acarreará la sensación, descrita muy bien por López, de que la experiencia chilena habría sido inferior, menos horrorosa, una mala copia o una imitación deslavada de la Schoa. A partir de ello es lógico que, como dice nuevamente López, se vuelva incómodo usar estas categorías y que se las utilice tan solo matizando con comillas. Lo ocurrido en Chile habría sido algo así como los "campos de concentración", pero sin los hornos crematorios, sin los trabajos forzados hasta la muerte, sin el Dr. Mengele. Unos campos de concentración entre comillas, es decir, no tan campos de concentración.

El echar mano de categorías acuñadas para el caso particular del nacismo con el objeto de pensar el chileno, tiene además como consecuencia el que se hace imposible ver la realidad extraordinaria, la novedad de lo ocurrido en nuestro país durante la dictadura militar. En las instalaciones chilenas tienen lugar modalidades del horror que no son menos horrorosas que las del nazismo, sino que son simplemente diferentes. En Chile hubo parrillas, casas de la risa, torturas permanentes y con múltiples modalidades, traslados una y otra vez de un lugar a otro, hubo vendas, hubo "poroteos", soplones y colaboradores, hubo desapariciones, juicios de guerra, fusilamientos y simulacros de fusilamientos, ley de fuga, Caravana de la Muerte, etc. Quien se deje guiar acríticamente por el caso del nacismo, quien insista en usar categorías y nombres acuñados para otros contextos, no reparará en la especificidad del horror de estos lugares, simplemente no será capaz de ver ninguno de estos fenómenos y, si los ve, nunca reparará en la extraordinaria particularidad del horror que hay en ellos: un horror, que, en tanto tal, es incomparable.

Jorge Montealegre hace notar que pasados ya más de cuarenta años desde el Golpe Militar, se vuelve necesario iniciar el trabajo de utili- 
zar una representación propia y, por lo tanto, nombres originales y adecuados para los fenómenos como los lugares de detención y de tortura. A juicio de este autor, se podría recurrir al imaginario nazi cuando sea pertinente, pero dicha apelación no puede ser "mecánica" (129), ni la identificación puede ser total. ${ }^{17}$ El riesgo de no operar con estas precauciones es que "las proyecciones y transferencias resulten deformadoras en un encuadre impertinente de la memoria que se desea rescatar" (Montealegre 129). La invitación es al "enfrentamiento creativo de las nuevas realidades que traen sus propias palabras e imágenes", el que podría estar siendo retrasado por un "mundo de la apariencia, que facilita las primeras relaciones de semejanza" (130). La utilización desmedida y acrítica del imaginario nazi puede terminar ocultando la realidad de lo ocurrido en Chile.

9. El trabajo nominativo al que invita Montealegre, sin embargo, no es algo que tengamos que comenzar, sino que ya está en marcha hace un buen tiempo. En efecto, hay nombres para estos lugares que se han acuñado en Chile, nombres que tienen la virtud de introducir matices y deferencias, que enriquecen el análisis sin necesidad de recurrir a la importación de terminología. En Chile, al igual que en la Alemania nazi, hubo diferentes tipos de lugares. Nubia Becker, por ejemplo, distingue entre "casas de tortura" y "campos de prisioneros" (Rojas 8) y Marcia Merino, por su parte, refiriéndose a Villa Grimaldi, observa que, en un primer momento (agosto de 1974) fue un "lugar de interrogatorio y tortura", pero que cuando se cierra José Domingo Cañas "pasó a ser, además de centro de tortura, un recinto clandestino masivo de detención" (82). Se trata de lugares con finalidades distintas que exigen, entonces, nombres diversos. En los testimonios, de hecho, es posible encontrar una enorme cantidad de nombres.

17 "El imaginario del Holocausto, con su excepcionalidad, propone un extremo ante el que se construyen las analogías. El símil, incluido el simulacro mediático, ayuda a pensar y explicar una realidad que permite las relaciones de semejanza entre cosas diferentes (llegar a la conclusión de que son incomparables ya supone una comparación). Pero la identificación no puede ser total ni la transferencia mecánica" (Montealegre 130). 
Además de "campo de concentración", que es el nombre más usado, se habla de campo de prisioneros, campo de detenidos [políticos], campo de reclusión, campo militar, campo de tortura y exterminio, campamento [militar] de prisioneros, campamento de concentración, campamento de detenidos, casas de tortura, centro [clandestino] de detención, centro de tortura, centro de reclusión, centro de flagelaciones, cárcel [secreta], etc.

En el caso de la literatura especializada prima también la utilización del término "campos de concentración". Sin perjuicio de ello, una parte de la crítica logra ver que la situación es diferente a la alemana y comienzan a usar términos más cercanos al lenguaje legal como "centros de reclusión o de detención", "centros de tortura"; en ocasiones se agrega el adjetivo "clandestinos" (Raffin 2006). Una propuesta particular para el caso chileno lo ofrecen María Fernanda Rojas y Macarena Paz Silva en su tesis/seminario de Arquitectura y Urbanismo (2004a 47-48). Ellas se basan en la clasificación hecha por el Informe Rettig, pero introducen algunas modificación y elaboran un listado diferenciando tipos de lugares: (1) "Lugares secretos de detención y tortura", (2) "Lugares solo de detención: espera o tránsito", (3) "Campamentos de Detenidos o Campos de Concentración", (4) "Recintos de detención pertenecientes a instituciones", (5) "Cárceles y penitenciarías". Loreto López (2009) sigue casi exactamente las distinciones de Rojas y Silva, pero introduce pequeñas modificaciones y un tipo nuevo. Ella habla de (1) "Lugares clandestinos o secretos de detención y tortura", (2) "Lugares de detención donde no se aplicaba tortura", (3) "Campamentos de detenidos", (4) "Recintos de detención pertenecientes a instituciones", (5) "Cárceles y penitenciarías" y (6) "Recintos para el funcionamiento interno de los Servicios de Inteligencia".

Como se puede observar, los nombres para designar estos lugares de horror de la dictadura chilena existen y se utilizan. Las denominaciones son múltiples y variadas, lo que permite hacer distinciones importantes entre los lugares. Si las observamos, encontramos que ellas están construidas del siguiente modo: en primer lugar, un sustantivo -campo, campamento, recinto, casa, cárcel, lugar, centroque va acompañado, en algunas oportunidades, de una mención 
específica acerca de quiénes son los que están allí encerrados -"de prisioneros" o "de detenidos"- y en otras ocasiones se agrega también una referencia a su función u objetivo -"de concentración", "de reclusión", "de tortura", "de interrogación", "de exterminio"-. En algunas oportunidades, se suma un adjetivo que alude a su condición de "clandestino" o "secreto". Las autoras antes mencionadas agregan a algunas de sus denominaciones una alusión expresa a que ciertos lugares pertenecen a "instituciones".

Algunos espacios son llamados campamentos, otros campos o recintos militares, en tanto que estaban ligados a las Fuerzas Armadas desde antes; otros ya eran cárceles o penitenciarías, y siguieron siéndolo aunque ya no alberguen solo delincuentes; algunos eran casas particulares que fueron utilizadas por las fuerzas de inteligencia y siguen siendo llamadas "casas". Preservar estas nomenclaturas tiene la virtud de que permite conservar una referencia a lo que estos lugares fueron antes de la dictadura, antes de ser utilizadas para la detención y la tortura de personas. Hay, por otra parte, sustantivos más descriptivos y con un uso más general que permiten referirse a los lugares sin alusión alguna a lo que fueron antes, como el término "lugar" o "centro", y que podrían utilizarse como nombres más genéricos: todos fueron lugares o centros, algunos de ellos fueron campamentos, casas, cárceles, etc.

En segundo término, la referencia a la calidad de los que eran allí encerrados en cuanto "prisioneros" o "detenidos", es una alusión directa a su estatus jurídico e indirectamente alude al momento histórico de existencia de un Centro. Durante la primera época después del Golpe de Estado, la denominación usada por los militares fue la de "prisionero de guerra" (PRIGUE), puesto que la necesidad y legitimidad de su intervención armada se basaba en la tesis de la guerra interna. Quien era encerrado, como cualquiera que es tomado prisionero en una guerra, era un "combatiente" y recibía el nombre de "prisionero de guerra".$^{18}$ Más adelante la denominación cambia por la de "detenido"

18 Vuskovic reproduce lo dicho por el Comandante a su llegada a Dawson: "Son llevados a presencia del comandante, quien les comunica que, de acuerdo con el Bando número 1, existe 'Estado de Guerra' y que, desde ese momento, son consi- 
con lo que se ingresa a un terreno más legal, en donde la detención es una "medida cautelar" que busca privar "temporalmente de libertad" a un sujeto por ser sospechoso de cometer un delito y con la finalidad de ponerlo a disposición de un juez competente. El estado de excepción instaurado en Chile a partir del 11 de septiembre de 1973 convierte a los militares en agentes competentes, habilitándolos para detener a los sospechosos y flexibiliza hasta el extremo los plazos y requisitos exigidos.

Por otra parte, en el nombre se agrega la finalidad. Las diferentes denominaciones hacen notar que no todos los lugares fueron creados para lo mismo. De hecho, en general estas diferentes funciones se daban en lugares diversos. La interrogación y la tortura se llevan a cabo habitualmente en centros especialmente destinados y habilitados para ello, por eso se habla específicamente de espacios "de tortura" específicamente. En esta categoría están, por ejemplo, Villa Grimaldi, Londres 38, José Domingo Cañas, El Palacio de las sonrisas de Punta Arenas, etc. Allí no se recluía, no se concentraba. Los prisioneros permanecían en estos Centros poco tiempo -por el día, un par de días, unas semanas como máximo-, solo para ser interrogados y durante sus estadías la tortura, en sentido amplio, era permanente. ${ }^{19}$ Los detenidos eran trasladados desde sus espacios "de reclusión" a los "de tortura" para luego ser devueltos, habitualmente en pésimo estado de salud.

Están, por supuesto, además, los casos menos frecuentes en que ambas tareas -detener y torturar- se dan en un solo lugar, entonces se habla de espacios "de detención y de tortura". En estos casos hay

derados 'prisioneros de guerra', y cualquiera insubordinación, intento de fuga o no cumplimiento de cualquiera orden sería castigado con el fusilamiento inmediato" (55). Más adelante, al ser entrevistados por la Cruz Roja y al mostrar las marcas de las tortura, ellos "nos aclaran que lo único que pueden hacer es exigir que se apliquen correctamente los acuerdos de la Convención de Ginebra sobre los Prisioneros de Guerra" (62).

19 Marcia Merino comenta que "Villa Grimaldi funcionaba como centro de interrogatorio y tortura para detenidos, que eran llevados selectivamente allí. De hecho a mí me llevaron desde Londres 38 a Grimaldi por lo menos en tres oportunidades" (35). 
que hacer una distinción importante, relativa al sentido de la tortura aplicada. Los espacios de interrogación y tortura estaban especialmente destinados a este fin y, por lo tanto, se trataba de la actividad principal y permanente que allí se realizaba. Hubo otros que eran "de detención o reclusión" en los que, además, se torturaba, siendo ambas actividades igualmente importantes en el recinto, en cuyo caso, es acertado referirse a ellos como "de detención y tortura". Pero además existieron aquellos en que la tortura solo fue utilizada esporádicamente y fundamentalmente como forma de castigo: a estos espacios no se les conoce con un nombre doble: son tan solo "de detención".

Finalmente, en estos espacios de interrogación y tortura en donde tiene lugar, en la mayor parte de los casos, el exterminio y la eliminación de sujetos (aunque hubo algunos lugares especialmente habilitados para esta última función), se incorpora en su nombre la especificación "de exterminio". La diferencia es, una vez más, la finalidad. Los centros de interrogación y tortura no tienen la finalidad primaria de eliminar o exterminar a nadie. De hecho, en los testimonios se da cuenta del revuelo que causa entre los militares el que algún prisionero esté en peligro de muerte a raíz de las torturas..$^{20}$ La presencia de médicos en las sesiones de interrogación, que incluso reviven a los prisioneros, da cuenta de que la finalidad no era la eliminación. En los centros llamados "de exterminio", por su parte, aunque se utiliza la tortura, su objetivo primario fue la eliminación de personas.

Como se ha visto, no parece necesario seguir usando el término "campo de concentración" como traducción del vocablo alemán Konzentratonslager, para designar los lugares en los que se encerró, torturó y asesinó en Chile. A estas alturas, existen nombres de muy interesante factura que sirven mucho mejor para denominar estos lugares. Usar el término "campo de concentración" a raíz de que no

20 Luego de recibir una bala en el pie estando en Londres 38, Luz Arce relata: "Escuché una discusión, alguien que parecía ser el oficial de turno dijo que no quería asumir que yo muriera ahí..." Luego reproduce el siguiente diálogo: "Sácala con cuidado. Si se nos muere aquí será peor. -Yo le dije, jefe, que la dejara tirada, ahora todo va a ser un lío" (65). 
habría términos para nombrar estos lugares es un argumento que puede haber tenido sentido en un primer momento, luego del Golpe Militar y en medio de la vorágine que ocasiona el horror, pero hoy claramente ya no es atendible.

10. Dado lo anterior, uno podría razonablemente preguntar, por qué entonces se sigue usando el nombre "campo de concentración" en Chile, si se trata de una mala traducción, si es una realidad muy diferente, si su utilización produce equívocos y problemas, si ni siquiera es ya necesario hacerlo. Una respuesta posible tiene que ver con el hecho de que simplemente es muy difícil, tal vez imposible, dejar de utilizar este nombre, sin que ello implique tener que renunciar a expresar la radicalidad de lo acontecido. En efecto, al usar el vocablo "campo de concentración" por tanto tiempo, se ha provocado no solo una vinculación con el caso alemán, sino que simultáneamente se ha ocasionado una suerte de dependencia de él. A raíz de esta insistencia en el uso del término, al horror que tuvo lugar en Chile durante la dictadura se le reconoce tan solo en la medida en que está emparentado con el caso alemán y no por sí mismo.

En este sentido es que María José López ha hablado de que tal vez ya no sería posible renunciar al uso del vocablo "campos de concentración". El riesgo de hacerlo consistiría en poner la experiencia chilena si no como inexistente, al menos en un lugar inferior, menos grave, menos dramático, menos radical que lo ocurrido en la Alemania nazi. "No se trata simplemente, de reconocer las diferencias de fenómenos particulares, sino de establecer una jerarquía geopolítica, que hace que nuestras experiencias, algo que ocurre en la periferia, siempre sería menos decisivo" (López, 2015b). La experiencia del campo de concentración ha sido tematizada y participa del imaginario colectivo y reflexivo como una situación límite, extrema, definitiva: el paralogismo del horror. Dejar de usar esta nomenclatura para designar lo ocurrido en Chile, podría implicar una renuncia a dicha radicalidad, sería poner la experiencia chilena en un grado más bajo en el barómetro del horror.

La única alternativa para evitar esta consecuencia sería potenciar el uso de las categorías propias y cargarlas semánticamente hasta el 
punto en que el horror que de ellas se desprenda dé cuenta de la radicalidad de lo vivido en Chile. María José López trae a colación una advertencia de Gabriel Salazar. El autor hace ver de qué manera el holocausto judío provocó la construcción de una serie de conceptos -totalitarismo nazi, fascista y estalinista- que luego jugaron un papel central en la historia de Occidente tanto hacia el pasado como hacia el futuro. "En cambio, en el Cono Sur no hemos construido, hasta hoy, un concepto similar. Y la humanidad no ha reconocido allí una ruptura histórica de trascendencia mundial. No hemos denunciado al mundo el holocausto sufrido por nuestros pueblos" (Salazar 27).

En Chile, en particular, no hemos logrado aún instalar categorías que marquen el enorme quiebre que implicó la dictadura, un quiebre que provocó un abismo cuya radicalidad aún no somos capaces de ver. Decía Patricio Marchant en 1989, que en un contexto en el que "todas las voces oficiales intentan negar la existencia de la catástrofe, la parálisis de la historia de Chile" la tarea del intelectual negativo consistía en comenzar el comentario de la catástrofe nacional, es decir, "en reconocer, en establecer la catástrofe como catástrofe" (222). Para ello se hace indispensable llevar a cabo una lucha por las categorías. Una que no pasa tanto por acuñarlas, pues muchas ya existe, sino más bien por situarlas, por instalarlas, por imponerlas. Categorías como catástrofe, por ejemplo, con la idea del quiebre definitivo que ello implica. En el mismo sentido, habrá que cargar e instalar términos como casa de tortura, lugar de detención, centro clandestino de exterminio y, con ello, desaparición forzada, fusilamiento, tortura, violación, exilio, etc., hasta que la experiencia se instale en el imaginario colectivo y reflexivo, chileno y mundial, como una situación límite, extrema del horror, tan horrorosa como lo fuera la de los Konzentrationslagern, pero diferente.

\section{Bibliografía}

Aibar Varas, Ibar. Sol y cielo abonaron mis sueños infinitos. Santiago de Chile: Emege Comunicaciones, 2002.

Arce, Luz. El Infierno. Chile Santiago: Ed. Océano [Planeta], 1993.

Arendt, Hannah. Los orígenes del totalitarismo. Madrid: Taurus, 1998. 
Avila, Mariela. "Campos de concentración de las dictaduras latinoamericanas. Una mirada filosófica", La Cañada. Revista del pensamiento filosófico en Chile 4 (2013): 215-231.

Calveiro, Pilar. Poder y desaparición. 1998. Buenos Aires: Colihue, 2006.

Carrasco, Rolando. Prigué. 1977. Santiago de Chile: Ediciones Aquí y Ahora, 1991.

Corvalán, Luis Alberto. Viví para contarlo. 1976. Santiago de Chile: Ediciones Tierra Mía, 2007.

Cozzi, Adolfo. Chacabuco, Pabellón 18, casa 89. Santiago de Chile: Sudamericana, 2002.

Die nationalsozialistischen Konzentrationslager. Eds. Herbert, Ulrich, Karin Orth y Christoph Dieckermann. Frankfurt am Main: Fischer-TaschenbuchVerlag, 2002.

Durán, Claudio. Autobiografía de un exjugador de ajedrez, Santiago de Chile: LOM, 2003.

Fernández, Oriana. " ¿'Dictadura' o 'régimen' militar? Connotados historiadores entran a la polémica por cambio en los textos escolares" entrevista a Gabriel Salazar. La Segunda. 5 ene. 2012: Nacional.

Gamboa, Alberto. Viaje al infierno. 1984. Santiago de Chile: Editorial Forja, 2010.

García, Juan Carlos. Crimen sin castigo: Valdivia, Neltume, Santiago, Tejas Verdes. Santiago de Chile: Mosquito comunicaciones, 2004.

Garretón, Manuel Antonio. "Prólogo. Tejas Verdes y nuestra memoria colectiva". Tejas Verdes: Diario de un campo de concentración en Chile. Santiago de Chile: CESOC/LOM, 1996. 5-16.

Garretón Merino, Roberto. "La experiencia concentracionaria chilena (19731977). Memoria, olvidos y silencios de un centro secreto de secuestro", Actuel Marx Intervenciones: Memorias en busca de Historia 6 (2008): 87100.

Informe Comisión Verdad y Reconciliación. Santiago de Chile: Gobierno de Chile, 1996.

Kaul, Friedich-Karl. "La congruencia entre el contenido y la apariencia de los sistemas de gobierno fascista establecidos en 1933 en Alemania y en 1973 en Chile", Denuncia y Testimonio. Tercera Sesión de la Comisión Internacional de Investigación de los Crímenes de la Junta Militar en Chile. Ciudad de México, 1975, 52-63. 
Königseder, Angelika. "Geschichte der nationalsozialistischen Konzentrationslager. Ein Kooperationsprojekt von Wissenschaft und Gedenkstätten", Dachauer Hefte: Öffentlichkeit und KZ. Was wusste die Bevölkerung? 17(2001): 203-206.

Larrocha Cejas, José. Retornando del Infierno. Santiago de Chile: La Simiente, 2009.

Lawner, Miguel. Retorno a Dawson. Santiago de Chile: LOM, 2004.

López, María José. "El 'desaparecido' como sujeto político: una lectura desde Arendt", Revista Franciscanum 57/164 (2015): 67-95.

"¿Qué decimos cuando decimo terror?", Coloquio Conflictos, préstamos e intercambios. Perspectivas sobre la investigación interdisciplinaria, Instituto de Estudios Avanzados, Usach, Santiago, 27 y 28 ago. 2015.

López, R. y Otero, E. Pedagogía del terror: un ensayo sobre la tortura. Santiago de Chile: Atena. 1989.

López, Loreto. "De los Centros de Detención a lugares de Memoria del terrorismo de Estado", Revista Praxis 15 (2009): 131-140.

Marchant, Patricio. "Desolación. Cuestión del nombre de Salvador Allende (1989-90)". Escritura y temblor. Santiago de Chile: Cuarto Propio, 2000. 213-234.

Montealegre, Jorge. "Construcción social de la memoria: presencia del imaginario del holocausto en testimonios latinoamericanos", Alpha 36 (2012): 119-134.

Orth, Karin. "Die Historiografie der Konzentrationslager und die neuere KZForschung", Archiv für Sozialistiche 47 (2007): 579-598.

Peris Blanes. La imposible voz: Memoria y representación de los campos de concentración en Chile: la posición del testigo. Santiago de Chile: Editorial Cuarto Propio, 2005.

Quijada, Aníbal. Cerco de púas. 1977. Santiago de Chile: Ediciones Fuego y Tierra, 1990.

Raffin, Marcelo. La experiencia del horror: Subjetividad y derechos humanos en las dictaduras y postdictaduras del Cono Sur. Buenos Aires: Del Puerto, 2006.

Rojas, Rodrigo. Jamás de rodillas (Acusación de un prisionero de la junta fascista de Chile). Moscú: Novosti, 1974.

Salazar, Gabriel. Dolencias históricas de la memoria ciudadana. Editorial Universitaria, 2012. 
Santos-Herceg, José. "Geografía humana del horror: Agentes, Prisioneros y Transeúntes". Ed. y Comp. Carolina Pizarro y José Santos. Revisitar la Catástrofe. La Prisión política del Chile dictatorial. Santiago de Chile: Editorial Pehuén, 2016, 167-186.

"Lugares de encuentro en los espacios del horror. Acercamiento testimonial a los Centros de Detención y/o Tortura chilenos", Kamchatka, Revista de análisis cultural 6 (2015): 651-664.

"Los Centros de Detención y/o Tortura en Chile hoy. Su desaparición como destino", Revista Izquierdas 26 (2015): 256-275.

Silva, M. y Rojas, F. "Sufrimiento y desapariciones. El manejo urbano-arquitectónico de la memoria urbana traumatizada". Universidad de Chile, Departamento de Urbanismo, Facultad de Arquitectura y Urbanismo, Santiago, 2004.

"El manejo urbano-arquitectónico de la memoria urbana traumatizada", Ciudad y Memorias. Desarrollo de Sitios de Conciencia en el Chile actual. Santiago de Chile: Corporación Parque por la paz Villa Grimaldi, 2011. 78-84.

Sofsky, Wolfgang. Die Ordnung des Terrors: Das Konzentrationslager. Frankfurt a.M.: S. Fischer, 1993.

Vidal, Hernán. Chile: poética de la tortura política. Santiago de Chile: Mosquito Editores, 2000.

Villegas, Sergio. Chile, El Estadio, los crímenes de la Junta Militar. Buenos Aires: Editorial Cartago, 1974.

Vuskovic, Sergio. Dawson. Madrid: Meridion, 1984. 